\title{
Mutations in Pol gene of hepatitis B virus in patients with chronic hepatitis $B$ before and after therapy with nucleoside/nucleotide analogues
}

\author{
D. JANUSZKIEWICZ-LEWANDOWSKA ${ }^{1,2,3}$, A. RUCKA ${ }^{3}$, A. KOWALA-PIASKOWSKA ${ }^{4}$, I. BERESZYNSKA ${ }^{4}$, I. \\ MOZER-LISEWSKA ${ }^{4}$, O. ZAJAC-SPYCHALA ${ }^{2}$, J. WYSOCKI ${ }^{5}$, J. NOWAK ${ }^{1}$
}

\begin{abstract}
${ }^{1}$ Institute of Human Genetics, Polish Academy of Sciences, Strzeszynska 32, Poznan, Poland; ${ }^{2}$ Department of Paediatric Oncology, Haematology and Transplantology, University of Medical Sciences, Poznan, Poland; ${ }^{3}$ Department of Medical Diagnostics, Dobra 35, Poznan, Poland; ${ }^{4}$ Department of Infectious Diseases, University of Medical Sciences, Poznan, Poland; ${ }^{5}$ University of Medical Sciences, Poznan, Poland
\end{abstract}

Received August 12, 2013; accepted April 25, 2014

\begin{abstract}
Summary. - Chronic hepatitis B (CHB) is one of the most common infections worldwide. Currently approved treatments of $\mathrm{CHB}$ include nucleoside/nucleotide analogues (NAs). However, long-term NA therapy is associated with accumulation of resistant mutations within the hepatitis B virus (HBV) polymerase gene. The incidence of naturally occurring HBV mutations leading to primary antiviral resistance has not been fully elucidated yet. The objective of present study was to detect the frequency of mutations within the HBV polymerase gene in 263 patients naïve to nucleoside/nucleotide analogues. Prevalence of HBV Pol gene mutations secondary to NA treatment in patients without pre-existing antiviral resistance mutations was also examined. Retrospective analysis showed that HBV Pol gene mutations were present in 7 out of 263 patients prior to the treatment. Mutations observed in NA-naïve CHB patients were associated only with resistance to lamivudine and adefovir. Compensatory mutations were observed as well. In the course of antiviral treatment, HBV Pol gene mutations were identified in 65 out of the remaining $256 \mathrm{CHB}$ patients (25.39\%), while no mutations of any type were detected in 160 patients $(62.5 \%)$. The profiles of detected mutations were comparable to those observed in other studies that focused on the analysis of clinically relevant NA-resistant mutations. In conclusion, we found out that antiviral resistance mutations may pre-exist in the overall viral population present in untreated patients, although the incidence of HBV Pol gene mutations in NA-naïe CHB patients was low and reached only up to $2.66 \%$. However, possible circulation and transmission of NAs-resistant HBV mutants in human population should be taken into account.
\end{abstract}

Keywords: chronic hepatitis B; drug resistance; HBV polymerase gene; nucleotide analogues

\section{Introduction}

Hepatitis B virus (HBV, the family Hepadnaviridae) is a small DNA virus capable of infecting only humans and certain primates (Liang, 2009; De Clerq, 2010; Seeger and Mason, 2000). Although its active replication occurs

E-mail: janusz@man.poznan.pl; phone: +48618221312. Abbreviations: $\mathrm{CHB}=$ hronic hepatitis $\mathrm{B} ; \mathrm{HBV}=$ hepatitis $\mathrm{B}$ virus; $\mathrm{NA}=$ nucleotide analogue; $\mathrm{HBs} \mathrm{Ag}=$ hepatitis $\mathrm{B}$ antigen primarily in liver cells, the virus was also demonstrated to be present outside hepatocytes, e.g. within the cells of lymphoid tissue, bile duct and kidney (Seeger and Mason, 2000; Zoulim and Locarnini, 2009). Since HBV reverse transcriptase has no proofreading activity, it promotes natural genetic variability of the virus (mutation ratio is about $10^{-7}$ to 1 nucleotide substitution per day) and increases the frequency of mutations, thus reducing sensitivity to antiviral drugs (Seeger and Mason, 2000). Due to the high rates of HBV mutations and replication means, 
the serum of $\mathrm{CHB}$ patients initially contains a heterogeneous viral population consisting of several HBV variants differing at least by single point mutations (Nafa, 2000). Inability to repair replication errors leads to accumulation of DNA sequence mutations of the individual variants. Most important factors responsible for the development of resistance to nucleoside/nucleotide analogues include high pre-treatment levels of HBV DNA and alanine aminotransferase (ALT) as well as high body mass index values (Zoulim, 2011; Locarnini, 2003; Stuyver, 2001; Locarnini and Mason, 2006). Drug resistance mutations are adaptive due to high genetic barrier and pharmacodynamic properties of drugs as well as higher replication rates of mutant HBV (Durendel, 2010).

HBV DNA polymerase (HBV Pol) gene consists of four domains: the terminal domain acting as primer for reverse transcriptase, a spacer region of unknown function; the reverse transcriptase/polymerase (RT/Pol domain) and ribonuclease $\mathrm{H} \mathrm{Pol}$ domain which is divided into five subdomains labeled A to E (Locarnini, 2008). Individual genotypes differ in the length of the HBV Pol gene mainly due to mutations in the spacer region. No differences were observed in the length of the RT domain (Niesters, 2010; Yildiz, 2011). Since the HBV genome is organized in overlapping reading frames, the polymerase gene overlaps the genes encoding the viral envelope. Consequently, mutations within the HBV Pol gene can produce changes in the overlapping envelope genes, particularly the $S$ gene (Yildiz, 2011; Arrese, 2011). In vitro studies have shown that HBV variants with mutations within the overlapping regions of genes encoding polymerase and envelope proteins are characterized by slower replication rates and smaller infectivity (Nafa, 2000; Arrese, 2011). At the same time, some HBV mutants became invisible to antibodies in blood due to mutations in surface antigens. This may contribute to the development of infections in people vaccinated against hepatitis $\mathrm{B}$ (Nafa, 2000; Locarnini, 2008; Arrese, 2011). In vitro studies confirmed a reduced ability of anti-HBs antibodies to bind $\mathrm{HBV}$ variants with mutations rtV173L+rtM204V+rtL180M within the polymerase gene and sE164D+sI195M within the HBsAg-encoding gene (Nafa, 2000; Arrese, 2011; Zöllner, 2005). Antiviral resistance mutations may pre-exist in the overall population of untreated patients infected with HBV. The incidence of naturally occurring HBV mutations leading to primary antiviral resistance has not been fully elucidated yet.

The objective of present study was to detect the frequency of mutations within the HBV Pol gene in patients naïve to nucleoside/nucleotide analogues. Prevalence of HBV Pol gene mutations secondary to NA treatment in patients without pre-existing antiviral resistance mutations was also examined.

\section{Materials and Methods}

Patients. The study population consisted of 263 NAs-naïve patients recruited between October 2009 and April 2012 at the Department of Infectious Diseases, University of Medical Sciences, Poznan, Poland. Study population consisted of 90 women and 173 men at the mean age of 37.1 years. All patients were diagnosed with $\mathrm{CHB}$ and were positive for HBsAg and anti-HBe, with HBV DNA levels of $>1000 \mathrm{IU} / \mathrm{ml}$. According to the guidelines of the National Health Fund in Poland, patients enrolled between year 2009 and April 2011 were treated with lamivudine (Zeffix) at $100 \mathrm{mg}$ /day as a the first-line CHB treatment. Resistance to the NA and the lack of response to previous treatment resulted in the use of other $\mathrm{NA}$ - adefovir (Hepsera) $10 \mathrm{mg} /$ day and/or entecavir (Baraclude) $1 \mathrm{mg} /$ day and/or tenofovir (Viread) $200 \mathrm{mg} /$ day. Starting from April 2011, peginterferon alpha-2a (Pegasys) was used in the firstline treatment of previously untreated $\mathrm{CHB}$ patients at the dose of $180 \mu \mathrm{g}$ once a week. If no elimination of HBV DNA was observed, entecavir (Baraclude) $1 \mathrm{mg} /$ day and/or tenofovir (Viread) $200 \mathrm{mg} /$ day was implemented as second-line therapy.

Methods. NucleoSpin Blood Kit (Machery-Nagel) was used for isolation of HBV DNA from the serum. Isolation procedure was carried out according to the manufacturer's instructions. INNOLiPA HBV DR v2/v3 (Innogenetics NV, Belgium) line probe assay was used for detection of resistance-carrying mutations within the HBV polymerase gene. The study was conducted using HBV DNA samples isolated at baseline (before treatment) and after 12, 24 , and 48 weeks of treatment, as well as whenever resistance to NAs was suspected.

\section{Results}

Retrospective analysis showed that HBV Pol gene mutations were present in 7 out of 263 patients prior to the treatment. Following mutations were detected in NA-naïve patients: rtL80V (2 patients), rtL80I (1 patient), rtL180M/ A181T/V (2 patients), rtM204V (1 patient) and rtM204I (1 patient). In four patients within this group, additional mutations appeared in the course of NA therapy, while in the remaining three patients mutations remained the same as those observed before treatment (Fig. 1). To date, no elimination of HBV DNA could be achieved in any of these seven patients.

Only the remaining $256 \mathrm{CHB}$ patients in whom no pre-treatment mutations were detected were included in further analyses. In the course of antiviral treatment, HBV Pol gene mutations were identified in 65 out of 256 CHB patients $(25.39 \%)$ while no mutations of any type were detected in 160 patients $(62.5 \%)$. In the remaining 31 patients (12.11\%), HBV DNA was eliminated from the serum, making determination of potential HBV Pol gene mutations impossible. 
Genotyping of the HBV Pol gene allowed us to determine the profile of mutation occurrence. Table 1 lists the detected mutations according to their frequency in individual patients in the course of NA treatment. Mutations resistant only to lamivudine were detected in 19 (29.23\%) out of 65 patients. Three $(4.62 \%)$ patients presented selective mutations associated with resistance to adefovir while isolated compensatory mutations were detected in another two (3.08\%) patients. In the remaining patients, complex HBV Pol gene mutations, including mutations determining resistance to lamivudine and/or adefovir as well as compensatory mutations, were detected. In these patients, the initially isolated mutations became more and more complex during treatment. No mutations associated with resistance to entecavir were detected. This might be due to the short, 6-month duration of entecavir use in our $\mathrm{CHB}$ patients.

\section{Discussion}

$\mathrm{HBV}$ variants may develop in $\mathrm{CHB}$ patients either as a result of positive selection by patients' own immune response, or during the treatment with NAs. Rates of primary NAs resistance in newly diagnosed HBV patients have been

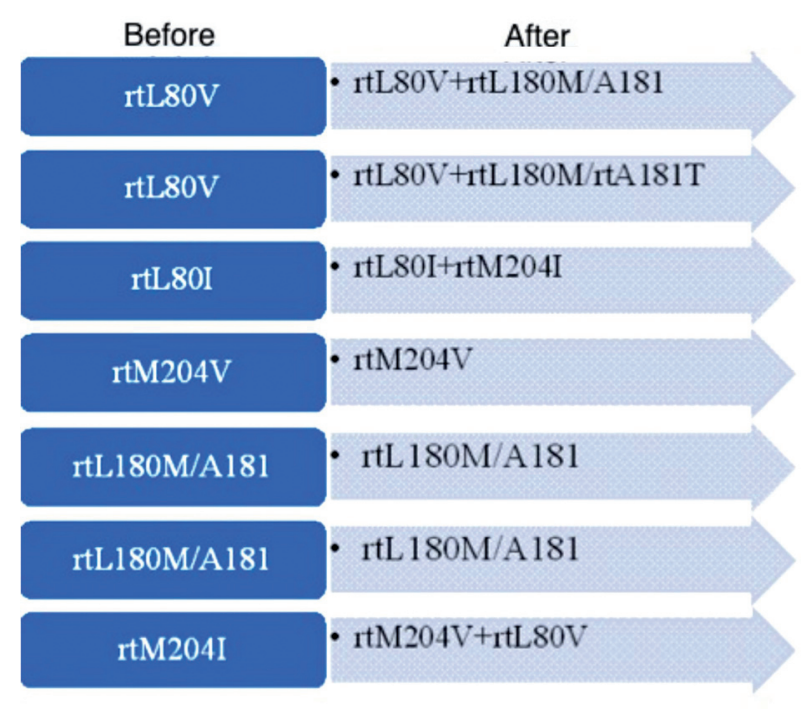

Fig. 1

HBV Pol gene mutations in CHB patients before and after NAs therapy Abbreviation of mutations: as an example - in rtL80V rt stands for reverse transcriptase and amino acid $\mathrm{L}$ at position 80 is replaced with amino acid $\mathrm{V}$; in $\mathrm{rtL} 180 \mathrm{M} / \mathrm{A} 181 \mathrm{~T} / \mathrm{V} r t$ stands for reverse transcriptase and amino acid $\mathrm{L}$ at position 180 is replaced with amino acid $\mathrm{M}$ and amino acid $\mathrm{A}$ at position 181 is replaced with amino acid $\mathrm{T}$ or $\mathrm{V}$.

Table 1. The incidence of mutations in HBV Pol gene in $\mathrm{CHB}$ patients following the NAs therapy

\begin{tabular}{|c|c|}
\hline Mutation & No. (\%) of patients with mutations \\
\hline $\mathrm{rtL} 180 \mathrm{M} / \mathrm{A} 181+\mathrm{rtM} 204 \mathrm{~V}$ & $15(23.1 \%)$ \\
\hline rtM204I & $7(10.77 \%)$ \\
\hline rtM204V & $7(10.77 \%)$ \\
\hline rtL180M/A181 & $5(7.69 \%)$ \\
\hline rtL80V+rtL80I+rtM204I & $4(6.15 \%)$ \\
\hline $\mathrm{L} 180 / \mathrm{rtA} 181 \mathrm{~T}$ & $3(4.62 \%)$ \\
\hline rtL80V+rtL180M/A181+rtM204V+rtM204I & $3(4.62 \%)$ \\
\hline rtL180/rtA181T+rtM204I & $2(3.08 \%)$ \\
\hline rtL80V & $2(3.08 \%)$ \\
\hline rtL80V+rtM204I & $2(3.08 \%)$ \\
\hline $\mathrm{rtL} 80 \mathrm{~V}+\mathrm{rtV} / \mathrm{G} 173 \mathrm{~L}+\mathrm{rtL} 180 \mathrm{M} / \mathrm{A} 181+\mathrm{rtM} 204 \mathrm{I}$ & $1(1.54 \%)$ \\
\hline $\mathrm{rtL} 80 \mathrm{~V}+\mathrm{L} 180 / \mathrm{A} 181$ & $1(1.54 \%)$ \\
\hline rtL80V+rtL180M/A181+rtM204V & $1(1.54 \%)$ \\
\hline rtL80V+rtL180M/rtA181T & $1(1.54 \%)$ \\
\hline rtL80V+rtM204V+rtM204I & $1(1.54 \%)$ \\
\hline rtL80V+rtL80I+rtL180M/rtA181T & $1(1.54 \%)$ \\
\hline rtL80I+rtM204I & $1(1.54 \%)$ \\
\hline rtL80I+rtL180M/A181+rtM204V & $1(1.54 \%)$ \\
\hline rtV/G173L+rtM204I & $1(1.54 \%)$ \\
\hline $\mathrm{rtV} / \mathrm{G} 173 \mathrm{~L}+\mathrm{rtL} 180 \mathrm{M} / \mathrm{A} 181+\mathrm{rtM} 204 \mathrm{~V}+\mathrm{rtN} 236 \mathrm{~T}$ & $1(1.54 \%)$ \\
\hline rtV/G173L+rtL180M/A181+rtM204V & $1(1.54 \%)$ \\
\hline L180/A181+rtM204V & $1(1.54 \%)$ \\
\hline rtL80V+rtL180M/rtA181T+rtM204V+rtM204I & $1(1.54 \%)$ \\
\hline rtM204V+rtM204I & $1(1.54 \%)$ \\
\hline rtL80V+rtL80I+rtL180M/A181+rtM204V & $1(1.54 \%)$ \\
\hline
\end{tabular}


reported only occasionally (Mirandola, 2011; Cuestas, 2010). Naturally occurring HBV variants with primary antiviral resistance were rarely observed. In a group of Argentine and Italian patients, the frequency of primary antiviral resistance did not exceed 5\% (Mirandola, 2011; Cuestas, 2010). Naturally occurring HBV variants were also tested in HIV/HBV-coinfected patients in Spain. Also in this case, the frequency of primary antiviral resistance was low (5.5\%) (Tuma, 2011). In our paper, we found out that antiviral resistance mutations may pre-exist in the overall viral population present in untreated patients, although the incidence of $\mathrm{HBV}$ Pol gene mutations in NA-naïe CHB patients was low and reached only up to $2.66 \%$. In line with the findings from other research groups, only mutations associated with resistance to lamivudine and adefovir, as well as compensatory mutations were observed in treatment-naïve patients in our study. As an exception, the Italian research group has additionally identified the rtM250L/V mutation typical for entecavir resistance (Mirandola, 2011). This might be due to the fact that the widespread use of lamivudine as oral therapy for chronic HBV infections was favored selection and thanks to worldwide circulation of resistant HBV strains. Transmission of such resistant $\mathrm{HBV}$ variants can be rapid, particularly within the population of HIV patients, who are more exposed to lamivudine as part of antiretroviral therapy.

We have traced the original mutations of the HBV Pol gene in the seven NA-naïve CHB patients over the course of treatment (Fig. 1). Only one out of four patients with primary resistance to lamivudine developed the compensatory mutation rtL80V. The remaining three of these four patients have retained their status of HBV Pol gene mutations. In another three patients with primary compensatory mutations, NA resistance mutations were induced over the course of treatment, including mutations resistant to lamivudine as well as adefovir.

Prevalence of HBV Pol gene mutations secondary to NA treatment in patients without pre-existing antiviral resistance mutations was also examined. The profile of HBV Pol gene mutations as detected in our study was similar to the results obtained by other groups (Cuestas, 2010; Tuma, 2011; Delaney, 2003). Compensatory mutations were identified in 24 patients. The most frequent mutation was $\mathrm{rtL} 80 \mathrm{~V} / \mathrm{I}$ (observed in 21 patients). The rtV173L substitution was identified in only 3 patients and was associated with mutation rtM204V/I. Similar drug resistance profile has also been reported in other studies (Zoulim and Locarnini, 2009; Arreses; 2011; Zöllner, 2005). Delaney et al. analyzed the prevalence of $\mathrm{rtV} 173 \mathrm{~L}$ mutation and its relation to rtL180M and rtM204V/I (Delaney, 2003). As shown by the study, the $\mathrm{rtV} 173 \mathrm{~L}$ mutation is always accompanied by the combined mutations rtL180M+rtM204V. In the same paper, the effect of the rtV173L mutation on the efficiency of virus replication in vitro was also examined. It was demonstrated that $\mathrm{rtV} 173 \mathrm{~L}$ mutation plays a compensatory role in lamivudine-resistant variants of $\mathrm{HBV}$, increasing the efficiency of replication in both wild-type and mutated HBV variants.

Changes within the HBV Pol gene were found in 65 out of 256 patients without pre-existing antiviral resistance mutations. Most frequently identified was lamivudineresistant mutation rtM204V, either as an isolated mutation or in combination with other mutations. In a majority of patients, mutation at codon rt204 was accompanied by rtL180M within the B subdomain of the Pol gene. Although the position rt180 is located outside the catalytic center of the enzyme, the rtL180M mutation is also associated with the development of resistance to lamivudine. A combination of $\mathrm{rtL} 180 \mathrm{M}+\mathrm{rtM} 204 \mathrm{~V} / \mathrm{I}$ mutations is often detected in HBV DNA obtained from patients after failure of lamivudine therapy, as already been reported in a number of studies (De Clercq, 2010; Zoulim and Locarnini, 2009; Arrese, 2011).

The treatment of chronic hepatitis B remains limited to monotherapy with either peginterferon-alpha or one of five different NAs. Viral suppression can be achieved in approximately $95 \%$ of $\mathrm{CHB}$ patients treated with new-generation NAs. However, the rate of $\mathrm{HBeAg}$ seroconversion ranges only from $20 \%$ to $30 \%$ after a follow-up of 5 years (Zoulim 2012). Accumulation of drug-resistant mutations within the polymerase gene of $\mathrm{HBV}$ is an important therapeutic challenge. The prevalence of variants with reduced susceptibility to lamivudine and other NAs generates the clinical need of finding new drugs with mechanisms of action different from that of polymerase HBV inhibitors.

To conclude, in view of the obtained results, showing that mutations within the HBV Pol gene associated with resistance to currently available NAs may pre-exist in patients who never received these drugs. One should be mindful of the possibility of circulation and transmission of $\mathrm{HBV}$ mutants with resistance to NAs in human population.

\section{References}

Arrese E, Basaras M, Blanco S, Ruiz P, Cisterna R (2011): Evolution of hepatitis $\mathrm{B}$ virus during long-term therapy in patients with chronic hepatitis B. Ann. Hepatol. 10, 434-740.

De Clercq E, Férir G, Kaptein S, Neyts J (2010): Antiviral treatment of chronic hepatitis B virus (HBV) infections. Viruses 2, 1279-1305. http://dx.doi.org/10.3390/ $\mathrm{v} 2061279$

Cuestas ML, Rivero CW, Minassian ML, Castillo AI, Gentile EA, Trinks J, León L, Daleoso G, Frider B, Lezama C, Galoppo M, Giacove G, Mathet VL, Oubi-a JR (2010): Naturally occurring hepatitis $B$ virus (HBV) variants with primary resistance to antiviral therapy and S-mutants with potential primary resistance to adefovir in Argentina. Antiviral Res. 87, 74-77. http://dx.doi.org/10.1016/j. antiviral.2010.04.005 
Delaney WE, Yang H, Westland CE, Das K, Arnold E, Gibbs CS, Miller MD, Xiong S (2003): The hepatitis B virus polymerase mutation $\mathrm{rtV} 173 \mathrm{~L}$ is selected during lamivudine therapy and enhances viral replication in vitro. J. Virol. 77, 11833-11841. http://dx.doi.org/10.1128/ JVI.77.21.11833-11841.2003

Durantel D (2010): Fitness and infectivity of drug-resistant and cross-resistant hepatitis B virus mutants: why and how is it studied? Antivir. Ther. 15, 521-527. http://dx.doi. org/10.3851/IMP1551

Liang TJ (2009): Hepatitis B: the virus and disease. Hepatology 49, 13-21. http://dx.doi.org/10.1002/hep.22881

Locarnini S (2003): Hepatitis B viral resistance: mechanisms and diagnosis. J. Hepatol. 39, S124-S132. http://dx.doi. org/10.1016/S0168-8278(03)00318-0

Locarnini S, Mason WS (2006): Cellular and virological mechanisms of HBV drug resistance. J. Hepatol. 44, 422-431. http://dx.doi.org/10.1016/j.jhep.2005.11.036

Locarnini S (2008): Primary resistance, multidrug resistance, and cross-resistance pathways in $\mathrm{HBV}$ as a consequence of treatment failure. Hepatol. Int. 2, 147-151. http://dx.doi. org/10.1007/s12072-008-9048-3

Mirandola S, Campagnolo D, Bortoletto G, Franceschini L, Marcolongo M, Alberti A (2011): Large-scale survey of naturally occurring HBV polymerase mutations associated with anti-HBV drug resistance in untreated patients with chronic hepatitis B. J. Viral. Hepat. 18, 212-216. http:// dx.doi.org/10.1111/j.1365-2893.2011.01435.x

Nafa S, Ahmed S, Tavan D, Pichoud C, Berby F, Stuyver L, Johnson M, Merle P, Abidi H, Trépo C, Zoulim F (2000): Early detection of viral resistance by determination of hepatitis $B$ virus polymerase mutations in patients treated by lamivudine for chronic hepatitis B. Hepatology 32, 1078-1088. http://dx.doi.org/10.1053/jhep.2000.19619

Niesters HG, Zoulim F, Pichoud C, Buti M, Shapiro F, D'Heuvaert N, Celis L, Doutreloigne J, Sablon E (2010): Validation of the INNO-LiPA HBV DR assay (version 2) in monitoring hepatitis $\mathrm{B}$ virus-infected patients receiving nucleoside analog treatment. Antimicrob. Agents Chemother. 54, 1283-1289. http://dx.doi.org/10.1128/AAC.00970-09

Seeger C, Mason WS (2000): Hepatitis B virus biology. Microbiol. Mol. Biol. Rev. 64, 51-68. http://dx.doi.org/10.1128/ MMBR.64.1.51-68.2000

Stuyver LJ, Locarnini SA, Lok A, Richman DD, Carman WF, Dienstag JL, Schinazi RF (2001): Nomenclature for antiviral-resistant human hepatitis B virus mutations in the polymerase region. Hepatology 33, 751-757. http:// dx.doi.org/10.1053/jhep.2001.22166

Tuma P, Pineda JA, Labarga P, Vidal F, Rodriguez C, Poveda E, Santos J, Gonzalez-García J, Sobrino P, Tural C, Soriano V; CoRIS Study Group (2011): HBV primary drug resistance in newly diagnosed HIV-HBV-coinfected individuals in Spain. Antivir. Ther. 16, 585-589. http:// dx.doi.org/10.3851/IMP1778

Yıldız O, Aygen B, Demirtürk N, Demirdal T, Inan D, Yıldırmak T, Kantürk A, Tütüncü E; Hepatitis B Study Group. Hepatitis B Study Group (2011): Lamivudine resistance mutations in patients infected with hepatitis B virus genotype D. World J. Gastroenterol. 17, 4987-4992. http://dx.doi. org/10.3748/wig.v17.i45.4987

Zoulim F, Locarnini S (2009): Hepatitis B virus resistance to nucleos(t)ide analogues. Gastroenterology 137, 15931608. http://dx.doi.org/10.1053/j.gastro.2009.08.063

Zoulim F (2011): Hepatitis B virus resistance to antiviral drugs: where are we going? Liver Int. 31, 111-116. http://dx.doi. org/10.1111/j.1478-3231.2010.02399.x

Zoulim F (2012): Are novel combination therapies needed for chronic hepatitis B? Antiviral Res. pii: S0166-3542 p. 00203-3.

Zöllner B, Sterneck M, Wursthorn K, Petersen J, Schröter M, Laufs R, Feucht HH (2005): Prevalence, incidence, and clinical relevance of the reverse transcriptase V207I mutation outside the YMDD motif of the hepatitis B virus polymerase during lamivudine therapy. J. Clin. Microbiol. 43, 2503-2505. http://dx.doi.org/10.1128/JCM.43.5.2503$\underline{2505.2005}$ 